\title{
Effective removal of the protective ligands from Au nanoclusters by ambient pressure nonthermal plasma treatment for $\mathrm{CO}$ oxidation
}

\author{
Yuan Tan a,b, Hua Liu a,b, Xiao Yan Liu a,*, Aiqin Wang a, Changjun Liu c, Tao Zhang a,b \\ a State Key Laboratory of Catalysis, iChEM (Collaborative Innovation Center of Chemistry for Energy Materials), Gold Catalysis Research Center, Dalian \\ Institute of Chemical Physics, Chinese Academy of Sciences, Dalian 116023, Liaoning, China \\ b University of Chinese Academy of Sciences, Beijing 100049, China \\ c Collaborative Innovation Center of Chemical Science and Engineering, School of Chemical Engineering and Technology, Tianjin University, Tianjin \\ 300072, China
}

\section{A R T I C L E I N F}

\section{Article history:}

Received 27 November 2017

Accepted 27 December 2017

Published 5 May 2018

\section{Keywords:}

Gold cluster

Plasma

Supported gold catalyst

Protective ligand

Carbon monoxide oxidation

\begin{abstract}
A B S T R A C T
We used a dielectric barrier discharge (DBD) plasma technique to eliminate the protective ligand of ZnAl-hydrotalcite-supported gold nanoclusters. We used X-ray powder diffraction, ultraviolet-visible spectrophotometry, thermogravimetric analysis, and high angle annular dark-field-scanning transmission electron microscopy characterization to show that the samples pretreated with/without DBD-plasma displayed different performances in CO oxidation. The enhanced activity was obtained on the plasma-treated samples, implying that the protective ligand was effectively removed via the plasma technique. The crystal structure of the plasma-treated samples changed markedly, suggesting that the plasma treatment could not only break the chemical bond between the gold and the protective agent but could also decompose the interlayer ions over the hydrotalcite support. The particle sizes of the gold after DBD-plasma treatment implied that it was a good way to control the size of the gold nanoparticles under mild conditions.
\end{abstract}

(C) 2018, Dalian Institute of Chemical Physics, Chinese Academy of Sciences. Published by Elsevier B.V. All rights reserved.

\section{Introduction}

Supported gold catalysts have attracted much attention recently due to their exceptionally high activity in low-temperature CO oxidation [1-6]. Their good performance in CO oxidation makes them potential candidates for many applications, such as environmental protection, clean energy conversion, and various important industrial processes [7-9]. The performance of gold catalysts in $\mathrm{CO}$ oxidation is strongly dependent on the particle sizes [10-13]. Thus, it was critical to control the size of the gold to get a highly active gold catalyst. It is generally ac- cepted that $\mathrm{Au}$ particle sizes below $5 \mathrm{~nm}$ have good performance $[12,13]$. However, due to the aggregation tendencies of gold particles during the synthesis process, the preparation of small gold particles with uniform dispersion is difficult.

The adsorption of colloidal gold on different metal oxides in liquid media has been studied extensively-especially to prepare gold catalysts smaller than $3 \mathrm{~nm}$ [14-16]. The regulation of gold particle sizes gives them considerable advantages in the synthesis of highly active gold catalysts. For example, Tsunoyama et al. [17] prepared Au clusters smaller than $1.5 \mathrm{~nm}$ and stabilized them with poly( $N$-vinyl-2-pyrrolidone) (PVP). They

\footnotetext{
* Corresponding author. Tel: +86-411-84379416; Fax: +86-411-84691570; E-mail: xyliu2003@dicp.ac.cn

This work was supported by the National Natural Science Foundation of China (21476227, 21522608, 21776271), the Strategic Priority Research Program of the Chinese Academy of Sciences (XDB17020100), the National Key Research \& Development Program of China (2016YFA0202801), the Youth Innovation Promotion Association CAS (2014163), and the Department of Science and Technology of Liaoning Province under contract of 2015020086-101.
}

DOI: 10.1016/S1872-2067(18)63018-9 | http://www.sciencedirect.com/science/journal/18722067 | Chin. J. Catal., Vol. 39, No. 5, May 2018 
found that catalysts with smaller sizes could donate more electronic charge to the CO molecules, resulting in higher activity in the aerobic oxidation of alcohol. Similarly, Fang et al. [18] prepared thiolate-ligand-protected $\mathrm{Au}_{25}$ nanoclusters deposited on different supports. They found that 2-nm particles showed higher activity in nitrobenzene hydrogenation. Although the colloidal gold might be highly efficient for obtaining the active gold catalyst with controllable size, the stabilizing ligands were always poisonous to the catalyst or restrained the reactant molecule from approaching the active sites $[19,20]$. Thus, it was necessary to remove the protective ligands for good catalytic performance with gold.

The most common approach to removing the protective ligands is high-temperature thermal treatment [21-23]. However, this method inevitably increased the particle sizes and caused uncontrollable particle deformation [21,23]. Hutchings' group recently reported a solvent extraction method for the removal of the stabilizing ligands without significantly increasing the particle sizes [24]. Zhang et al. [25] reported a strategy for the mild deprotection of thiol ligands using peroxide as an oxidant. In the past several decades, the DBD-plasma technique has been applied to many areas for the removal of the template from various materials [26-31]. This typically uses a nonthermal treatment technique at low temperature and atmospheric pressure [26,27].

In the field of catalysis, DBD-plasma treatment might be an effective way to obtain highly dispersed catalysts without exposing the sample to high temperature [28]. It is also a unique way to enhance the interaction between the metal and the support [30]. In addition, DBD-plasma treatment can be used to synthesize a novel material with useful properties [31]. Thus, plasma treatment might be efficient for obtaining highly active supported gold nanocatalyst with controllable sizes.

Previously, we prepared a ZnAl-hydrotalcite-supported $\mathrm{Au}$ nanocatalyst for the hydrogenation of functionalized nitroarenes. The catalytic performance was strongly dependent on the removal of the protective ligands [32]. Thus, in this work, we tried to study the ligand effect of supported gold nanoclusters for CO oxidation - this is a typical structure-sensitive reaction. We applied non-thermal plasma treatment to remove the different protective ligands with various treatment conditions. We studied the influence of plasma treatment on the properties and performance of the catalysts used for CO oxidation. The X-ray powder diffraction (XRD), ultraviolet-visible (UV-vis), thermogravimetric (TGA) and high angle annular dark-field-scanning transmission electron microscopy (HAADFSTEM) data were used to evaluate the impact of plasma treatment on the removal efficiency and the size distributions of the gold particles.

\section{Experimental}

\subsection{Preparation of the precursors}

The thiolated $\mathrm{Au}_{25}$ clusters were synthesized according to the literature [33]. Typically, $5.0 \mathrm{~mL}$ of the $\mathrm{HAuCl}_{4}$ solution (110 mmol/L) and $150 \mathrm{~mL}$ of the cysteine solution (5.5
mmol/L) were successively added into $200 \mathrm{~mL}$ of ultrapure water. Then, $30 \mathrm{~mL}$ of $1 \mathrm{~mol} / \mathrm{L} \mathrm{NaOH}$ solution was introduced into the above mixture. After stirring for $15 \mathrm{~min}$, an excess of $\mathrm{NaBH}_{4}$ was added, followed by vigorous stirring for $3 \mathrm{~h}$. The products were collected and washed with an ethanol/water mixture $(V / V=4: 1)$ to obtain the Au25 clusters.

The PVP-protected Au clusters were prepared by adding the aqueous solution of $\mathrm{HAuCl}_{4}(1 \mathrm{mmol} / \mathrm{L}, 50 \mathrm{~mL})$ into the PVP solution in a $0{ }^{\circ} \mathrm{C}$ ice bath [34]. The PVP solution was prepared by dissolving $555 \mathrm{mg}$ of PVP (K30, WM = 30,000) in $50 \mathrm{ml}$ of distilled water. After stirring for $0.5 \mathrm{~h}$ at low speed (150 r/min), the freshly prepared aqueous solution of $\mathrm{NaBH}_{4}(0.5 \mathrm{mmol})$ was quickly added into the above suspension under vigorous stirring. The color of the mixture immediately turned from pale yellow to dark brown with many bubbles, indicating the formation of AuPVP clusters. After $3 \mathrm{~h}$, the mixture was concentrated with a centrifugal ultrafiltration concentrator (SartoriusStedim Biotech, Vivaspin20) featuring a 10-kDa MWCO membrane. The concentrated solution was then dried via lyophilization to obtain the AuPVP clusters.

The ZnAl-hydrotalcite support was prepared as follows. Solution A was obtained by adding $0.21 \mathrm{~mol} \mathrm{Zn}\left(\mathrm{NO}_{3}\right)_{2} \cdot 6 \mathrm{H}_{2} \mathrm{O}$ and $0.07 \mathrm{~mol} \mathrm{Al}\left(\mathrm{NO}_{3}\right)_{3} \cdot 9 \mathrm{H}_{2} \mathrm{O}$ into $200 \mathrm{~mL}$ of ultrapure water. Solution $\mathrm{B}$ was prepared by adding $0.438 \mathrm{~mol}$ of $\mathrm{NaOH}$ and 0.113 mol of $\mathrm{Na}_{2} \mathrm{CO}_{3}$ into $200 \mathrm{~mL}$ of ultrapure water. Solution A was then slowly added to solution B under constant stirring at 75 ${ }^{\circ} \mathrm{C}$. After stirring for $24 \mathrm{~h}$, the mixture was filtered and washed with distilled water several times. The precipitate was dried in an oven at $80^{\circ} \mathrm{C}$ overnight to obtain the $\mathrm{ZnAl}$-hydrotalcite (HT).

Supported $\mathrm{Au}$ nanoclusters were synthesized via the impregnation method [32]. In a typical synthesis, $30 \mathrm{mg}$ of thiolated $\mathrm{Au}_{25}$ clusters or $100 \mathrm{mg}$ of the PVP protected Au clusters were dissolved in $25 \mathrm{~mL}$ of ultrapure water. Then, $2.00 \mathrm{~g}$ of the ZnAl-HT support was added to the above suspension while stirring. After $1 \mathrm{~h}$, the products were washed with deionized water and collected by centrifugation. The residue was then dried in an $80^{\circ} \mathrm{C}$ oven overnight to obtain the samples. These were named as $\mathrm{Au}_{25} / \mathrm{ZnAl}-\mathrm{HT}$ or AuPVP/ZnAl-HT.

\subsection{Plasma treatment}

The resulting precursors were decomposed under the DBD-plasma equipment (Corona Lab., CTP-2000K) composed of a voltage regulator, a plasma generator, a digital oscilloscope, and a DBD-plasma reactor (Fig. 1). Briefly, the sample ( 1.0 g) was loaded on a quartz plate that was packed in the discharge cell for air plasma treatment. The range of distances between the two dielectric barriers was $8 \mathrm{~mm}$. The high voltage was 7.5 $\mathrm{kV}$ at a frequency of $22.5 \mathrm{kHz}$. The duration of plasma treatment was 5 min each. This was repeated several times. The sample prepared in this way was designated as Au25/ZnAl-P-5 or AuPVP/ZnAl-P-5 (the 5 implies that the sample was treated for $5 \mathrm{~min}$ ).

\subsection{Characterization}

XRD spectra were determined on a PW3040/60 X'Pert PRO 


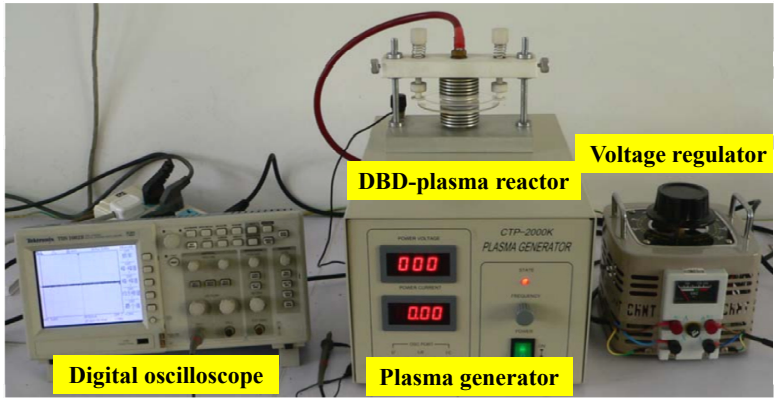

Fig. 1. DBD-plasma equipment.

(PANalytical) diffractometer equipped with a $\mathrm{Cu} K_{\alpha}$ radiation source $(\lambda=0.15432 \mathrm{~nm})$ operating at $40 \mathrm{kV}$ and $40 \mathrm{~mA}$. The continuous mode was used at a scanning speed of $5^{\circ} / \mathrm{min}$ in the $2 \theta$ range from $10^{\circ}$ to $80^{\circ}$. UV-vis spectra were recorded on a Cintra (GBC) apparatus with $\mathrm{BaSO}_{4}$ as the reference at room temperature. A continuous mode scanning speed of 100 $\mathrm{nm} / \mathrm{min}$ was used from 400 to $800 \mathrm{~nm}$. The HAADF-STEM images and energy-dispersive X-ray (EDX) spectra were recorded on a JEOL JEM-2100F microscope equipped with a STEM dark-field (DF) and Oxford detectors at $200 \mathrm{kV}$. The TGA experiment was conducted on a TA Q600 analyzer, and the samples ( 4-10 mg) were loaded on a $100-\mu \mathrm{L} \mathrm{Al}_{2} \mathrm{O}_{3}$ crucible and heated from 30 to $900{ }^{\circ} \mathrm{C}$ at a heating rate of $10{ }^{\circ} \mathrm{C} / \mathrm{min}$ under air $(\sim 50 \mathrm{~mL} / \mathrm{min})$.

\subsection{CO oxidation}

The catalytic performance of the catalysts for CO oxidation was evaluated in a fixed-bed flow reactor. $100 \mathrm{mg}$ of the supported Au25 catalyst and $50 \mathrm{mg}$ of the supported AuPVP catalyst were loaded into a quartz tube at atmospheric pressure. The temperature range of the reaction was $\sim 30-400{ }^{\circ} \mathrm{C}$ with a reactant gas composition of $1 \% \mathrm{CO}, 1 \% \mathrm{O}_{2}$, and $98 \% \mathrm{He}$. The flow rate of the reactant gas was controlled at $33.33 \mathrm{~mL} / \mathrm{min}$ with space velocities of the reaction (GHSV) of $20000 \mathrm{~h}^{-1}$ for the Au25/ZnAl-HT samples and $40000 \mathrm{~h}^{-1}$ for the AuPVP/ZnAl-HT samples. The gas mixture passing through the catalyst powder was detected using an online Agilent 7890 gas chromatograph equipped with a TDX-01 column. The CO conversion was calculated with the change of $\mathrm{CO}$ concentration in the inlet and outlet gases.

\section{Results and discussion}

\subsection{Removal of protective ligands}

The gold loading over the $\mathrm{Au}_{25} / \mathrm{ZnAl}-\mathrm{HT}$ and AuPVP/ $\mathrm{ZnAl}-\mathrm{HT}$ catalyst before and after DBD-plasma treatment is listed in Table 1. Under plasma treatment, the Au loading on the $\mathrm{Au}_{25} / \mathrm{ZnAl}-\mathrm{HT}$ and $\mathrm{Au}_{25} / \mathrm{ZnAl}-\mathrm{P}-25$ catalyst increased from $0.9 \%$ to $1.0 \%$, suggesting that some ligands on the $\mathrm{Au}_{25} /$ ZnAl-P-25 catalyst had been effectively removed. As the plasma treatment time increased from 25 to 75 min, the Au loading remained within $\sim 1.0 \%-1.1 \%$, suggesting that the ligands on the catalysts might be difficult to remove at this stage. The pro-
Table 1

The actual loadings of $\mathrm{Au}$ over the plasma-treated samples at different treatment times.

\begin{tabular}{lccrc}
\hline Catalyst & $\begin{array}{c}\text { Weight } \\
(\mathrm{mg})\end{array}$ & $\begin{array}{c}\text { Volume } \\
(\mathrm{mL})\end{array}$ & $\begin{array}{r}\text { Content } \\
(\mathrm{ppm})\end{array}$ & $\begin{array}{c}\text { Loading of } \\
\mathrm{Au}^{*}(\%)\end{array}$ \\
\hline $\mathrm{Au}_{25} / \mathrm{ZnAl}-\mathrm{HT}$ & 25.3 & 25 & 8.83 & 0.9 \\
$\mathrm{Au}_{25} / \mathrm{ZnAl}-\mathrm{P}-25$ & 25.2 & 25 & 11.50 & 1.1 \\
$\mathrm{Au}_{25} / \mathrm{ZnAl}-\mathrm{P}-50$ & 25.4 & 25 & 9.85 & 1.0 \\
$\mathrm{Au}_{25} / \mathrm{ZnAl}-\mathrm{P}-75$ & 25.1 & 25 & 10.75 & 1.1 \\
$\mathrm{Au}_{25} / \mathrm{ZnAl}-\mathrm{P}-100$ & 25.1 & 25 & 10.21 & 1.0 \\
$\mathrm{Au}_{25} / \mathrm{ZnAl}-\mathrm{P}-150$ & 25.7 & 25 & 10.18 & 1.0 \\
$\mathrm{AuPVP} / \mathrm{ZnAl}-\mathrm{HT}$ & 100.0 & 25 & 7.98 & 0.20 \\
$\mathrm{AuPVP} / \mathrm{ZnAl}-\mathrm{P}-50$ & 48.3 & 10 & 12.14 & 0.25 \\
\hline
\end{tabular}

${ }^{*}$ Determined by ICP-OES.

tective ligands on the Au clusters were too few to be detected; thus, the increased Au loadings were probably attributable to the removal of the interlayer ions over the hydrotalcite support. In comparison, the Au loading from the plasma-treated AuPVP/ZnAl-HT sample and untreated sample were $0.25 \%$ and $0.20 \%$, respectively. Similarly, the increased Au loading implied the effective removal of the interlayer ligands on this support.

During plasma treatment, a distinct color change was observed in the $\mathrm{Au}_{25} / \mathrm{ZnAl}-\mathrm{HT}$ sample (Fig. 2). The fresh sample not treated under the plasma instrument was faint yellow at the beginning (Fig. 2(a)). After initiating the DBD-plasma treatment, the sample immediately turned light purple. This suggested that some reaction might occur between the gold atoms and the support. As the treatment time increased from 25 to $150 \mathrm{~min}$, the color of the catalysts turned from light purple to dark purple (Fig. 2(b) (f)), which indicated that more ligands bound to the gold might be removed. At the same time, some of the particles might be aggregated. A similar phenomenon was also observed in the plasma-treated AuPVP/ZnAl-HT sample. The color of the sample was light pink at the beginning. After plasma treatment, the color became dark pink, suggesting that some of the ligands were removed during this process (data not shown).

We performed TGA to obtain quantitative data regarding ligand removal (Fig. 3). The experiment used Au25/ZnAl-HT

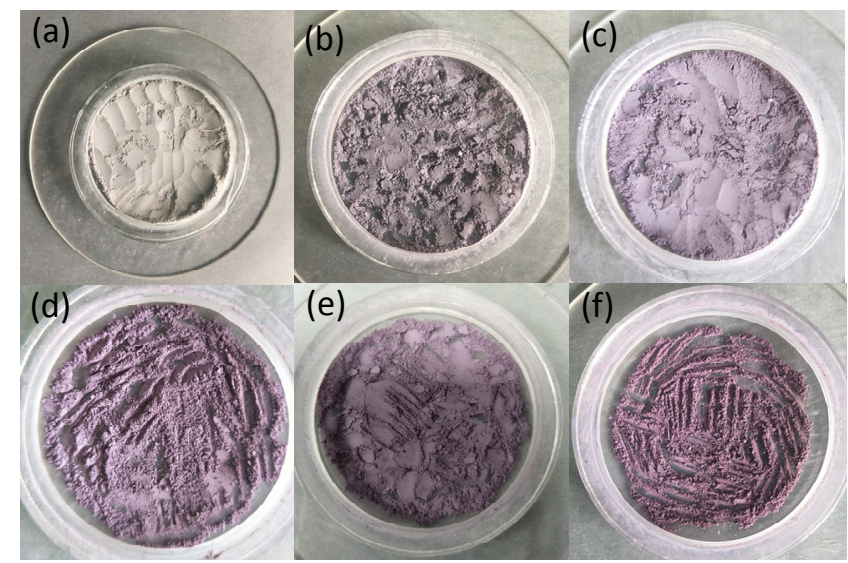

Fig. 2. Visualization of the template removal of the $\mathrm{Au}_{25} / \mathrm{ZnAl}-\mathrm{HT}$ sample at different treatment times using DBD-plasma with an input voltage and current of $75 \mathrm{~V}$ and $2 \mathrm{~A}$, respectively. (a) $0 \mathrm{~min}$; (b) $25 \mathrm{~min}$; (c) $50 \mathrm{~min}$; (d) $75 \mathrm{~min}$; (e) $125 \mathrm{~min}$; (f) $150 \mathrm{~min}$. 
and AuPVP/ZnAl-HT samples before and after DBD-plasma treatment under air at a heating rate of $10{ }^{\circ} \mathrm{C} / \mathrm{min}$. When the calcination temperature increased, the change in weight decreased for all samples. An obvious inflection point appeared at $300{ }^{\circ} \mathrm{C}$, which indicated that most of the ligands decomposed below $300{ }^{\circ} \mathrm{C}$. In other words, the ligands were harder to remove at higher temperatures. For example, the $\mathrm{Au}_{25} / \mathrm{ZnAl}-\mathrm{HT}$ sample had a weight loss of $25 \%$ at $300{ }^{\circ} \mathrm{C}$ and a weight loss of $31 \%$ at the final temperature. The AuPVP/ZnAl-HT sample had a weight loss of $23 \%$ at $300{ }^{\circ} \mathrm{C}$ and a weight loss of $31 \%$ at the final temperature. These observations indicated that both catalysts had more ligands that tended to decompose before 300 ${ }^{\circ} \mathrm{C}$ than those at higher temperatures. For comparison, the $\mathrm{Au}_{25} / \mathrm{ZnAl}-\mathrm{P}-25, \mathrm{Au}_{25} / \mathrm{ZnAl}-\mathrm{P}-75$, and AuPVP/ZnAl-P-50 samples had a final weight loss of $23 \%, 20 \%$, and $19 \%$, respectively. The weight loss after $400{ }^{\circ} \mathrm{C}$ was negligible. This implied that about $10 \%$ of the ligands on the catalysts could be effectively removed under the DBD-plasma treatment. The gap of the weight loss (about 3\%) between the $\mathrm{Au}_{25} / \mathrm{ZnAl}-\mathrm{P}-25$ and $\mathrm{Au}_{25} / \mathrm{ZnAl}-\mathrm{P}-75$ catalysts also suggested the possibility of removing the protective ligand by increasing the time of the plasma treatment from $25 \mathrm{~min}$ to $75 \mathrm{~min}$.

\subsection{Crystal structure and particle sizes}

We conducted XRD measurements to investigate the crystal structure of DBD plasma-treated samples and the non-plasmatreated samples (Fig. 4). The $\mathrm{Au}_{25} / \mathrm{ZnAl}-\mathrm{HT}$ and AuPVP/ ZnAl-HT samples without plasma treatment showed obvious characteristic reflections with a typical layered structure of hydrotalcite and a series of narrow, symmetric, and strong peaks at $11^{\circ}, 23^{\circ}, 35^{\circ}, 39^{\circ}, 47^{\circ}, 61^{\circ}$, and $62^{\circ}$. After plasma treatment, all samples had a structure similar to $\mathrm{ZnO}$, suggesting that the structure of $\mathrm{ZnAl}$ hydrotalcite had transformed to multiple oxides after DBD-plasma treatment. This agreed well with our previous data [32]. This also means that plasma treatment could not only break the chemical bond between the gold and the protective agent but could also remove the hydroxyl and carbonyl groups at the interlayer of the support.

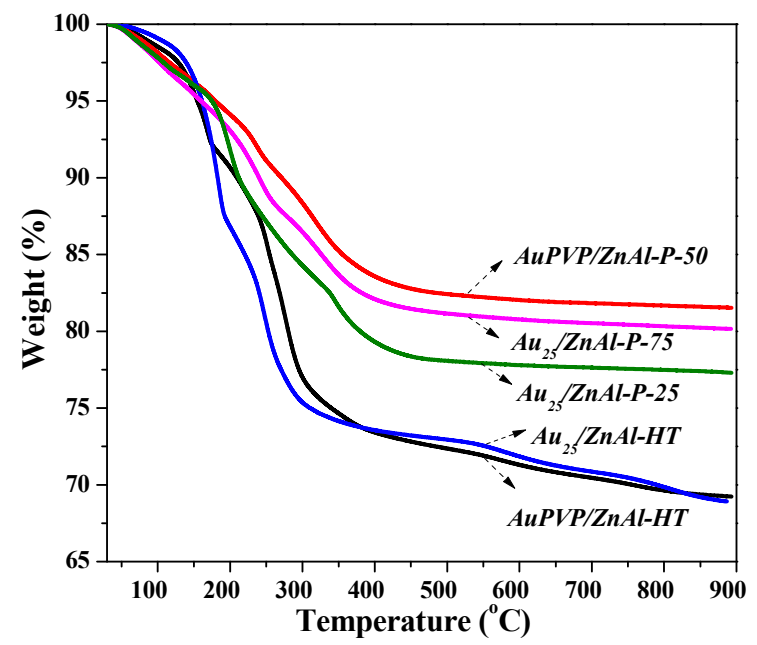

Fig. 3. TGA results of the untreated samples and the plasma-treated samples under air.

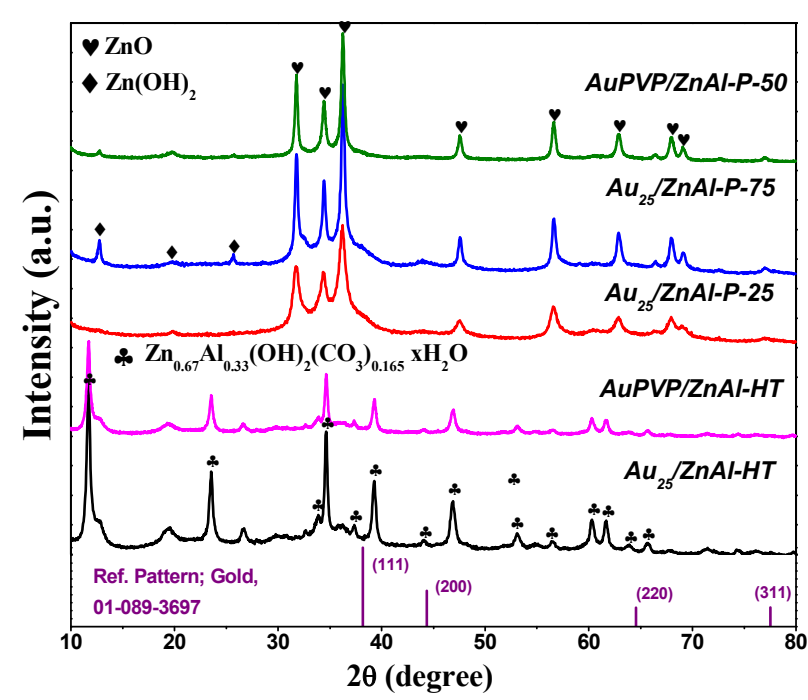

Fig. 4. XRD patterns of the samples before and after the plasma treatment.

Of note, some traces of the $\mathrm{Zn}(\mathrm{OH})_{2}$ species were first observed with the Au25/ZnAl-P-75 sample. This is very different from previous reports [32], in which the $\mathrm{Zn}(\mathrm{OH})_{2}$ species does not appear during calcination. The result also suggested that some different reactions might occur during plasma treatment. In addition, no sample had a gold diffraction peak, suggesting that the gold particles were too small to be detected or that the loading was too low.

We further characterized the samples by UV-vis spectroscopy (Fig. 5). The gold particle sizes and light absorption properties were deduced. The Au25/ZnAl-HT and AuPVP/ZnAl-HT samples were flat absorbers, suggesting that the samples have no absorption in the ultraviolet-visible range. After DBD-plasma treatment, the Au25/ZnAl-P-25, Au25/ZnAl-P-75 and AuPVP/ZnAl-P-50 samples exhibited an obvious band at $\sim 520 \mathrm{~nm}$, which was attributed to the surface plasma resonance of the gold particles. Meanwhile, the broad band of the $\mathrm{Au}_{25} / \mathrm{ZnAl}-\mathrm{P}-25$ and $\mathrm{Au}_{25} / \mathrm{ZnAl}-\mathrm{P}-75$ samples suggested the presence of small-sized gold.

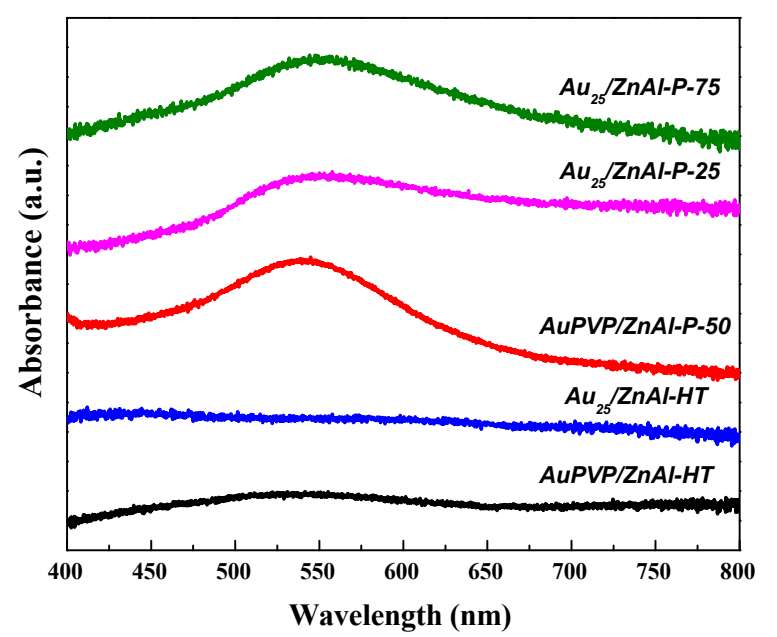

Fig. 5. UV-vis spectra of the untreated samples and the plasma-treated samples. 
The HAADF-STEM images of the supported gold nanoclusters before and after plasma treatment are illustrated in Fig. 6. The results indicate that the gold particles in all the samples were highly dispersed on the ZnAl-HT support. The different densities of the gold particles are due to the different gold loadings on the Au25/ZnAl-HT and AuPVP/ZnAl-HT samples.

We randomly selected more than 200 particles to calculate the mean particle size (Fig. 7 histograms of size). The mean particle sizes of the Au25/ZnAl-HT sample before and after plasma treatment were $1.4 \pm 0.4 \mathrm{~nm}$ (Fig. 7(a)) and $1.7 \pm 0.7$ nm (Fig. 7(b)), respectively. In addition, the average particle sizes of AuPVP/ZnAl-HT sample before and after plasma treatment were $2.4 \pm 1.1 \mathrm{~nm}$ (Fig. 7(c)) and $3.7 \pm 1.6 \mathrm{~nm}$ (Fig. $7(d)$ ), respectively. These results implied that the plasma treatment would not lead to the severe agglomeration of gold particles, which is beneficial to catalysis because only gold particles below $5 \mathrm{~nm}$ are efficient for CO oxidation $[12,13]$. Thus, we speculated that the supported gold clusters under the DBD-plasma treatment might have activity for CO oxidation.

\subsection{Catalytic performance for $\mathrm{CO}$ oxidation}

We used CO oxidation as a model reaction to test the catalytic performance of the plasma-treated and non-plasmatreated samples (Fig. 8). Significantly enhanced activity was achieved with the plasma-treated samples. The reaction was performed with excessive oxygen and the same volume ratio of CO $(1 \%)$ and $\mathrm{O}_{2}(1 \%)$. Helium was used as the balance gas. During the low temperature stage, the $\mathrm{Au}_{25} / \mathrm{ZnAl}-\mathrm{HT}$ and Au25/ZnAl-P-25 catalysts showed little activity, but the $\mathrm{Au}_{25} / \mathrm{ZnAl}-\mathrm{P}-75$ catalyst displayed increased activity. The plasma-treated samples had obviously enhanced activity as the reaction temperature increased from 120 to $280{ }^{\circ} \mathrm{C}$. The im-

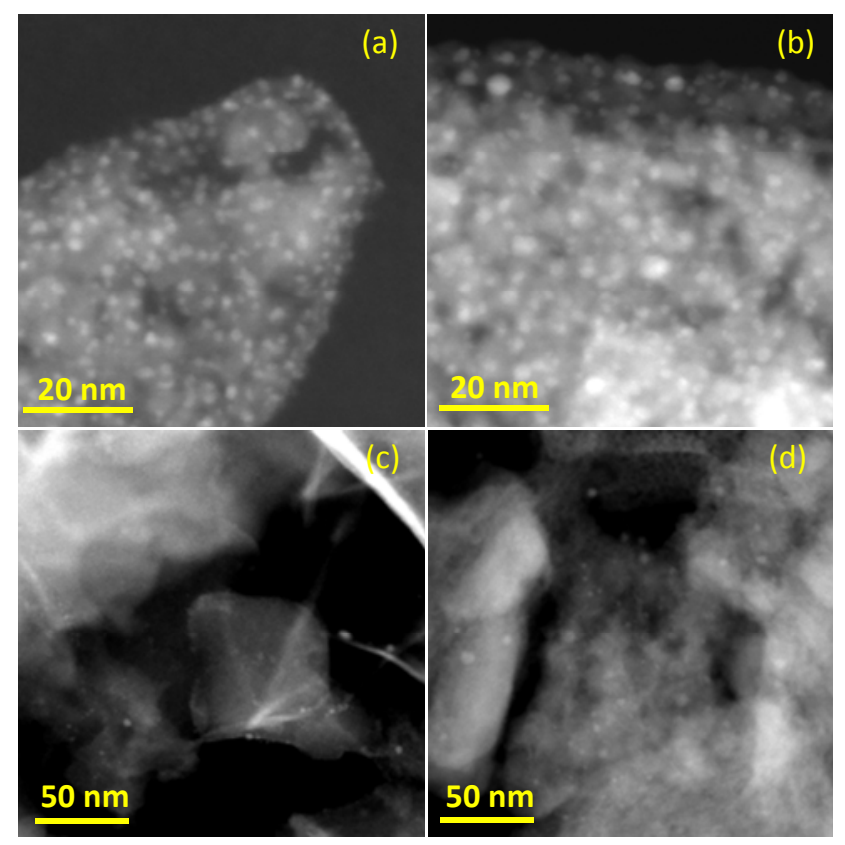

Fig. 6. HAADF-STEM images of the untreated and the plasma-treated samples. (a) $\mathrm{Au}_{25} / \mathrm{ZnAl}-\mathrm{HT}$; (b) $\mathrm{Au}_{25} / \mathrm{ZnAl}-\mathrm{Plasma;}$ (c) AuPVP/ZnAl-HT; (d) AuPVP/ZnAl-Plasma.
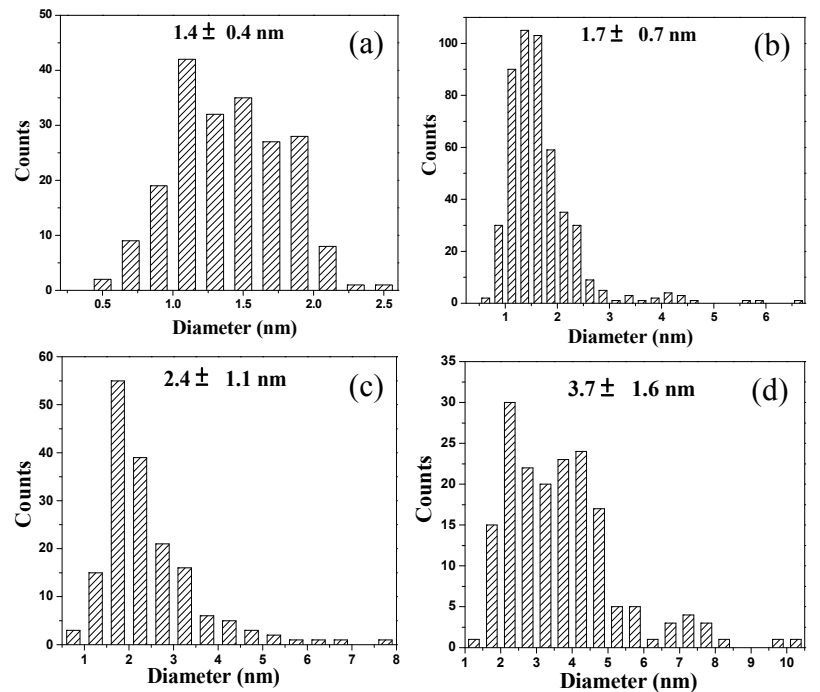

Fig. 7. Size distributions of the untreated and the plasma-treated samples. (a) Au25/ZnAl-HT; (b) Au25/ZnAl-Plasma; (c) AuPVP/ZnAl-HT; (d) AuPVP/ZnAl-Plasma.

provement was more pronounced on catalysts with long-term plasma treatment. The same trend was also seen over the AuPVP/ZnAl-P-50 catalyst. Compared with previous reports, the supported $\mathrm{Au}_{25} / \mathrm{CeO}_{2}$ catalysts had an optimized catalytic activity after being pretreated at high temperature [20]. This suggested that the thiolate ligand packed on the gold nanoclusters was poisonous for $\mathrm{CO}$ oxidation. Hence, plasma treatment over the $\mathrm{Au}_{25} / \mathrm{ZnAl}-\mathrm{HT}$ sample in this case played an important role in the removal of the protective ligand and offered good performance for $\mathrm{CO}$ oxidation.

Arrhenius plots for CO oxidation over the plasma-treated samples are depicted in Fig. 9. Despite the different types of protective ligands, the apparent activation energies $\left(E_{\mathrm{a}}\right)$ for plasma-treated $\mathrm{Au}_{25} / \mathrm{ZnAl}-\mathrm{HT}$ and AuPVP/ZnAl-HT samples were almost identical $(\sim 1.4 \mathrm{~kJ} / \mathrm{mol}$ for Au25/ZnAl-P-75 and $\sim 1.2 \mathrm{~kJ} / \mathrm{mol}$ for AuPVP/ZnAl-50). This suggested a similar cat-

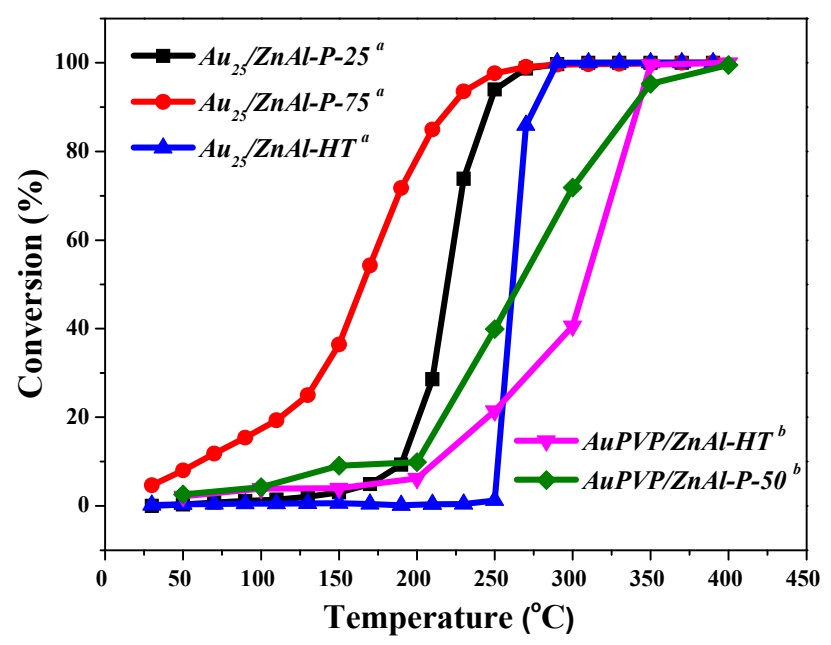

Fig. 8. Different gold samples for $\mathrm{CO}$ oxidation reaction. Reaction conditions: $1 \% \mathrm{CO} / 1 \% \mathrm{O}_{2} / 98 \% \mathrm{He}$, flow rate $33.33 \mathrm{~mL} / \mathrm{min}$; a catalyst 100 mg with GHSV of $20000 \mathrm{~mL} \mathrm{~g}^{-1} \mathrm{~h}^{-1}$; b catalyst $50 \mathrm{mg}$ with GHSV of $40000 \mathrm{~mL} \mathrm{~g}^{-1} \mathrm{~h}^{-1}$. 


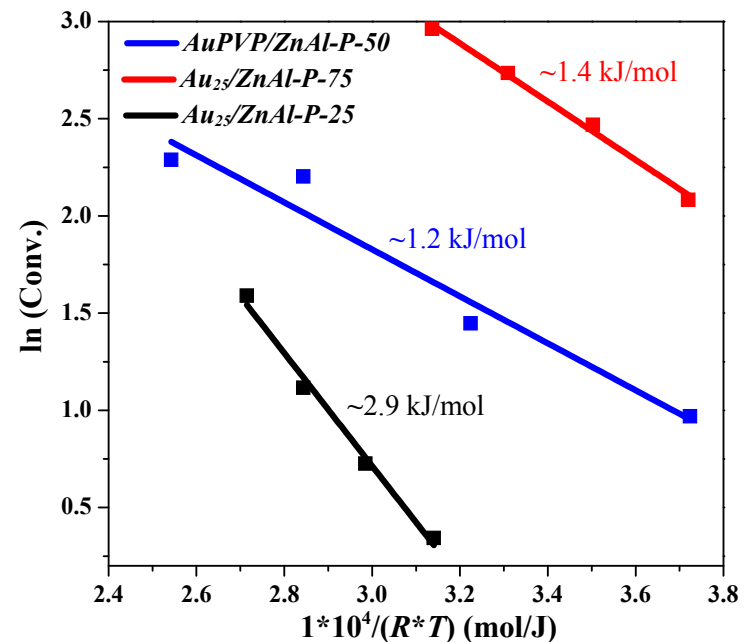

Fig. 9. Arrhenius plots for CO oxidation over the plasma-treated samples.

alytic mechanism and/or active species in these catalysts. Meanwhile, the final state of Au on the surface after DBD-plasma treatment might be the same in both catalysts $[8,35,36]$.

DFT calculations suggest that the CO molecule could be preferentially adsorbed on the gold particles, but oxygen adsorption does not occur on the gold single crystal surface due to the activation barrier that exists during dissociation of the adsorbed oxygen [4,37]. This suggested that mobile molecular oxygen was first activated on the interface of the support, followed by its dissociation. The spillover of oxygen to the active centers on the gold particles then reacted with $\mathrm{CO}$ to form the $\mathrm{CO}_{2}[8,9,38]$. In our case, the efficient removal of protective ligands facilitates the $\mathrm{CO}$ approach to the gold particles for reaction with oxygen. Concurrently, the low-coordinated gold species created by plasma treatment might benefit CO adsorption. Of note, the $E_{\mathrm{a}}$ for the $\mathrm{Au}_{25} / \mathrm{ZnAl}-\mathrm{P}-25$ catalyst $(\sim 2.9$ $\mathrm{kJ} / \mathrm{mol}$ ) was higher than these for the Au25/ZnAl-P-75 ( 1.4 $\mathrm{kJ} / \mathrm{mol})$ and AuPVP/ZnAl-P-50 ( $1.2 \mathrm{~kJ} / \mathrm{mol})$ catalysts. This is because the reaction mechanism and/or the active species were different over the Au25/ZnAl-P-25 catalyst versus over the other two samples. This might be because of the higher coverage of the protective ligand on the $\mathrm{Au}_{25} / \mathrm{ZnAl}-\mathrm{P}-25$ sample. This resulted in a different reaction pathway for the $\mathrm{CO}$ oxidation reaction. Moreover, the apparent activation energy was as low as $\sim 1.2-2.9 \mathrm{~kJ} / \mathrm{mol}$. This is close to value of the $\mathrm{Au} / \mathrm{TiO}_{2}$ catalyst $[37,39]$ and implied that the catalytic activity could be detected at any temperature when the gold particles were sufficiently small [37]. Further study is needed to elucidate these points.

The strong synergistic effects between gold and the support-as well as the formation of the interface-impacted the catalytic activity of CO oxidation [39]. The TGA and XRD results suggest that the weight losses of the catalysts pretreated by plasma not only originated from the removal of the protecting ligands of the thiolated $\mathrm{Au}_{25}$ nanoclusters but also from the change in the support (from hydrotalcite to composite oxides). Therefore, the interaction between gold and the support might also influence the data. Thus, DBD-plasma treatment might play an important role in creating active gold species and enhancing the interaction between $\mathrm{Au}$ and the support. This greatly increases the catalytic activity of the Au25/ZnAl-HT and AuPVP/ZnAl-HT catalysts.

\section{Conclusions}

We eliminated the protective ligand from supported gold nanoclusters at atmospheric pressure using non-thermal plasma treatment. We used XRD, UV-vis, TGA, and HAADF-STEM characterization of samples before and after DBD-plasma treatment to show their different performance in CO oxidation. Enhanced activity was seen with plasma-treated samples. This implied effective removal of the protective ligand. The crystal structure of the catalysts changed after plasma treatment, but the mean gold particle sizes remained constant. These results suggested that the plasma treatment could remove the hydroxyl group and the carbonyl group on the interlayer of the support and could break the chemical bond between the gold and the protective agent. This work provides an effective method to control the synthesis of small gold nanoparticles under mild conditions.

\section{References}

[1] M. Haruta, T. Kobayashi, H. Sano, N. Yamada, Chem. Lett., 1987, 405-408.

[2] M. Haruta, S. Tsubota, T. Kobayashi, H. Kageyama, M. J. Genet, B. Delmon, J. Catal., 1993, 144, 175-192.

[3] S. D. Lin, M. Bollinger, M. A. Vannice, Chem. Lett., 1993, 17, 245-262.

[4] H. H. Kung, M. C. Kung, C. K. Costello, J. Catal., 2003, 216, 425-432.

[5] B. T. Qiao, J. Lin, A. Q. Wang, Y. Chen, T. Zhang, J. Y. Liu, Chin. J. Catal., 2015, 36, 1505-1511.

[6] B. T. Qiao, J. X. Liang, A. Q. Wang, J. Y. Liu, T. Zhang, Chin. J. Catal., 2016, 37, 1580-1587.

[7] M. Haruta, Chem. Rec., 2003, 3, 75-87.

[8] G. C. Bond, D. T. Thompson, Gold Bull., 2000, 33, 41-50.

[9] G. J. Hutchings, Gold Bull., 1996, 29, 123-130.

[10] J. D. Grunwaldt, C. Kiener, C. Wögerbauer, A. Baiker, J. Catal., 1999, 181, 223-232.

[11] S. Tsubota, D. A. H. Cunningham, Y. Bando, M. Haruta, Stud. Surf. Sci. Catal., 1995, 91, 227-235.

[12] N. Phonthammachai, Z. Y. Zhong, J. Guo, Y. F. Han, T. J. White, Gold Bull., 2008, 41, 42-50.

[13] H. Falsig, B. Hvolbœk, I. S. Kristensen, T. Jiang, T. Bligaard, C. H. Christensen, J. K. Nørskov, Angew. Chem. Int. Ed., 2008, 47, 4835-4839.

[14] T. Tsukuda, H. Tsunoyama, H. Sakurai, Chem. Asian J., 2011, 6, 736-748.

[15] S. Yamazoe, K. Koyasu, T. Tsukuda, Acc. Chem. Res., 2014, 47, 816-824.

[16] H. F. Qian, M. Z. Zhu, Z. K. Wu, R. C. Jin, Acc. Chem. Res., 2012, 45, 1470-1479.

[17] H. Tsunoyama, N. Ichikuni, H. Sakurai, T. Tsukuda, J. Am. Chem. Soc., 2009, 131, 7086-7093.

[18] J. Fang, J. G. Li, B. Zhang, X. Yuan, H. Asakura, T. Tanaka, K. Teramura, J. P. Xie, N. Yan, Nanoscale, 2015, 7, 6325-6333.

[19] X. T. Nie, H. F. Qian, Q. J. Ge, H. Y. Xu, R. C. Jin, ACS Nano, 2012, 6, 6014-6022. 


\title{
Graphical Abstract
}

Chin. J. Catal., 2018, 39: 929-936 doi: 10.1016/S1872-2067(18)63018-9

Effective removal of the protective ligands from Au nanoclusters by ambient pressure nonthermal plasma treatment for Co oxidation

Yuan Tan, Hua Liu, Xiao Yan Liu *, Aiqin Wang, Changjun Liu, Tao Zhang

Dalian Institute of Chemical Physics, Chinese Academy of Sciences; University of Chinese Academy of Sciences; Tianjin University

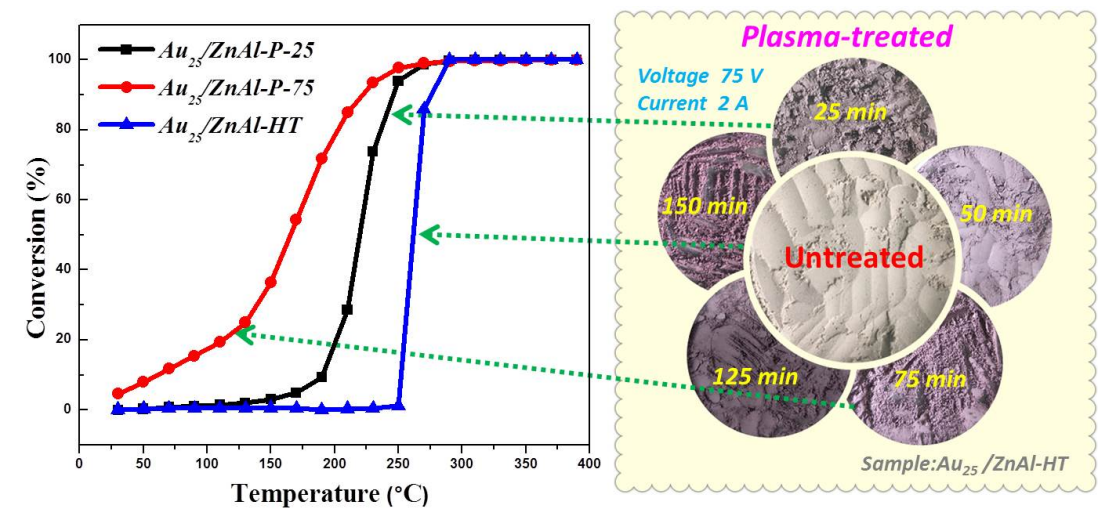

The protective ligands of supported gold nanoclusters could be effectively eliminated via atmospheric pressure non-thermal plasma treatment. This greatly enhanced their catalytic activity for $\mathrm{CO}$ oxidation.

[20] Z. L. Wu, D. E. Jiang, A. K. P. Mann, D. R. Mullins, Z. A. Qiao, L. F. Allard, C. J. Zeng, R. C. Jin, S. H. Overbury, J. Am. Chem. Soc., 2014, 136, 6111-6122.

[21] H. F. Yin, C. Wang, H. G. Zhu, S. H. Overbury, S. H. Sun, S. Dai, Chem. Commun., 2008, 4357-4359.

[22] L. Wen, J. K. Fu, P. Y. Gu, B. X. Yao, Z. H. Lin, J. Z. Zhou, Appl. Catal. B, 2008, 79, 402-409.

[23] H. F. Yin, Z. Ma, M. F. Chi, S. Dai, Catal. Lett., 2010, 136, 209-221.

[24] J. A. Lopez-Sanchez, N. Dimitratos, C. Hammond, G. L. Brett, L. Kesavan, S. White, P. Miedziak, R. Tiruvalam, R. L. Jenkins, A. F. Carley, D. Knight, C. J. Kiely, G. J. Hutchings, Nat. Chem., 2011, 3, 551-556.

[25] B. Zhang, J. Fang, J. G. Li, J. J. Lau, D. Mattia, Z. Y. Zhong, J. P. Xie, N. Yan, Chem. Asian J., 2016, 11, 532-539.

[26] X. Y. Liu, C. Y. Mou, S. Lee, Y. N. Li, J. Secrest, B. W. L. Jang, J. Catal,, 2012, 285, 152-159.

[27] S. Zhang, X. S. Li, B. Zhu, J. L. Liu, X. B. Zhu, A. M. Zhu, B. W. L. Jang, Catal. Today, 2015, 256, 142-147.

[28] P. Cools, N. De Geyter, E. Vanderleyden, P. Dubruel, R. Morent, Plasma Chem. Plasma Processing, 2014, 34, 917-932.
[29] Y. Liu, Y. X. Pan, P. Y. Kuai, C. J. Liu, Catal. Lett., 2010, 135, 241-245.

[30] J. J. Wang, Z. Y. Wang, C. J. Liu, ACS Appl. Mater. Interface, 2014, 6, 12860-12867.

[31] Z. Wang, Y. Zhang, E. C. Neyts, X. Cao, X. Zhang, B. W. L. Jang, C. J. Liu, ACS Catal., 2018, 8, 2093-2110.

[32] Y. Tan, X. Y. Liu, L. L. Zhang, A. Q. Wang, L. Li, X. L. Pan, S. Miao, M. Haruta, H. S. Wei, H. Wang, F. J. Wang, X. D. Wang, T. Zhang, Angew. Chem. Int. Ed., 2017, 56, 2709-2713.

[33] X. Yuan, B. Zhang, Z. T. Luo, Q. F. Yao, D. T. Leong, N. Yan, J. P. Xie, Angew. Chem. Int. Ed., 2014, 53, 4623-4627.

[34] H. Tsunoyama, H. Sakurai, Y. Negishi, T. Tsukuda, J. Am. Chem. Soc., 2005, 127, 9374-9375.

[35] M. S. Chen, D. W. Goodman, Science, 2004, 306, 252-255.

[36] N. Weiher, A. M. Beesley, N. Tsapatsaris, L. Delannoy, C. Louis, J. A. van Bokhoven, S. L. M. Schroeder, J. Am. Chem. Soc., 2007, 129, 2240-2241.

[37] M. Haruta, M. Daté, Appl. Catal. A, 2001 222, 427-437

[38] M. Haruta, Gold Bull., 2004, 37, 27-36.

[39] M. Haruta, CATTECH, 2002, 6, 102-115.

\section{常压低温等离子体有效去除催化CO氧化的金原子团簇的保护剂}

\author{
谭 媛 ${ }^{\mathrm{a}, \mathrm{b}}$, 刘 华 ${ }^{\mathrm{a}, \mathrm{b}}$, 刘晓艳 ${ }^{\mathrm{a},{ }^{*}}$, 王爱琴 ${ }^{\mathrm{a}}$, 刘昌俊 ${ }^{\mathrm{c}}$, 张 涛, ${ }^{\mathrm{a}, \mathrm{b}}$
}

$\mathrm{a}$ 中国科学院大连化学物理研究所催化基础国家重点实验室, 能源材料化学协同创新中心, 金催化中心, 辽宁大连 116023

${ }^{\mathrm{b}}$ 中国科学院大学, 北京 100049

${ }^{\mathrm{c}}$ 天津大学化学化工协同创新中心, 天津 300072

摘要: 采用介质阻挡放电等离子体技术可以在低温、常压下实现对纳米金催化剂中保护基团的有效去除. 本文通过对不同 保护基团(聚乙烯吡咯烷酮和半胱氨酸)保护的金催化剂进行等离子体预处理, 发现采用该技术能有效去除载体中的层间阴 离子, 还可能将金原子与保护基团之间的化学键打断. 通过X射线粉末衍射对等离子体处理后的样品和未经处理的样品进 行表征, 发现经等离子体处理后的样品, 载体从水滑石结构变为复合氧化物结构, 这说明等离子体处理可将载体中的羟基 
和羰基除去, 从而引起载体结构变化. 热重分析结果显示, 经等离子体处理后的样品失重量(19\%-23\%)与未处理样品的失 重量(31\%)相比差10\%左右, 这说明采用该方法可以在一定程度上去除纳米金表面保护基团和载体的层间阴离子. 用紫外可见光谱和高角环形暗场像-扫描透射电子显微镜对催化剂中金颗粒的尺寸分布和平均粒径进行分析, 发现金颗粒在等离 子体处理过后其粒径没有发生严重聚集, 平均粒径由未处理时的1.4-1.7 nm轻微长大至2.4-3.7 nm.

以含硫醇化合物(半胱氨酸)保护的金原子团簇催化剂为例考察了等离子体不同处理时间的影响, 发现随着处理时间从 $25 \mathrm{~min}$ 延长至 $150 \mathrm{~min}$, 样品的颜色从浅紫色变为暗紫色. 结合XRD和TGA等结果可知, 随着处理时间的延长, 催化剂中保 护基团的去除度逐渐提高. $\mathrm{CO}$ 氧化反应活性评价结果显示, 与未经处理的样品相比, 经等离子体处理后的样品催化 $\mathrm{CO}$ 氧 化反应活性有明显提高, 且随预处理时间延长, 活性有提高的趋势. 动力学测试结果表明, 经等离子体处理后的样品催化 $\mathrm{CO}$ 氧化的表观活化能低至 $1.2-2.9 \mathrm{~kJ} / \mathrm{mol}$, 接近于文献中报道的 $\mathrm{Au} / \mathrm{TiO}_{2}$ 催化剂. 这说明作为一种催化剂处理方法, 介质阻 挡放电等离子体技术可以有效去除催化剂中的保护剂, 且因其处理条件相对温和, 可在一定程度上保持金颗粒尺寸的稳 定, 这对于控制合成负载型小尺寸的金催化剂具有重要意义.

关键词: 金原子团簇; 等离子体; 纳米金催化剂; 有机保护基团; 一氧化碳氧化

收稿日期: 2017-11-27. 接受日期: 2017-12-27. 出版日期: 2018-05-05.

*通讯联系人. 电话: (0411)84379416; 传真: (0411)84691570; 电子信箱: xyliu2003@dicp.ac.cn

基金来源：国家自然科学基金(21476227, 21522608, 21776271); 中国科学院战略性先导科技专项(XDB17020100); 国家重点研发 计划“纳米科技”重点专项(2016YFA0202801); 中国科学院青年创新促进会(2014163); 辽宁省科技厅(2015020086-101).

本文的电子版全文由Elsevier出版社在ScienceDirect上出版(http://www.sciencedirect.com/science/journal/18722067). 